\title{
On the Use of Genetic Algorithm to Optimize the On-board Energy Management of a Hybrid Solar Vehicle
}

\author{
M. Sorrentino*, I. Arsie, R. Di Martino and G. Rizzo \\ Department of Mechanical Engineering, University of Salerno, 84084 Fisciano (SA) - Italy \\ e-mail: msorrentino@unisa.it - iarsie@unisa.it -rdimartino@unisa.it -grizzo@unisa.it \\ * Corresponding author
}

\begin{abstract}
Résumé - De l'usage de l'algorithme génétique pour l'optimisation de la gestion de l'énergie embarquée d'un véhicule hybride solaire - Cet article traite du développement d'un prototype de Voiture Hybride Solaire (VHS) avec structure en série. Cette activité a également été menée dans le cadre du projet Leonardo, financé par l'Union Européenne, sur les «Systèmes de conversion de l'énergie et leur impact sur l'environnement », un projet de recherche à vocation pédagogique. Une étude portant sur le contrôle de supervision pour les véhicules hybrides solaires et des tests routiers préliminaires y sont présentés. Les résultats préalablement obtenus par un modèle de conception VHS optimale ont confirmé les avantages de ces véhicules par rapport aux voitures conventionnelles en cas d'utilisation intermittente en ville (voiture urbaine). Ils ont également démontré que les voitures VHS étaient réalisables d'un point de vue économique dans un avenir proche. Grâce au groupe motopropulseur en série adopté pour le prototype de VHS, une utilisation intermittente du Moteur à Combustion Interne (MCI) alimentant le générateur électrique est possible, évitant ainsi un fonctionnement du moteur en charge partielle peu efficace. La meilleure trajectoire de puissance du MCI est déterminée par l'optimisation de l'algorithme génétique, responsable de la consommation de carburant et de l'état de charge de la batterie, en prenant également en compte la contribution solaire en mode de stationnement. La configuration expérimentale utilisée pour l'enregistrement des données, la surveillance et le contrôle du prototype en temps réel est également présentée, de même que les résultats obtenus au cours des différents essais routiers abordés.
\end{abstract}

Abstract - On the Use of Genetic Algorithm to Optimize the On-board Energy Management of a Hybrid Solar Vehicle - This paper deals with the development of a prototype of Hybrid Solar Vehicle (HSV) with series structure. This activity has been also conducted in the framework of the European Union funded Leonardo project "Energy Conversion Systems and Their Environmental Impact", a project with research and educational objectives. A study on supervisory control for hybrid solar vehicles and some preliminary tests performed on the road are presented. Previous results obtained by a model for HSV optimal design have confirmed the relevant benefits of such vehicles with respect to conventional cars in case of intermittent use in urban driving (city-car), and that economical feasibility could be achieved in a near future. Due to the series-powertrain adopted for the HSV prototype, an intermittent use of the ICE (Internal Combustion Engine) powering the electric generator is possible, thus avoiding part-load low-efficient engine operations. The best ICE power trajectory is determined via genetic algorithm optimization accounting for fuel mileage as well as battery state of charge, also considering solar contribution during parking mode. The experimental set up used for data logging, real-time monitoring and control of the prototype is also presented, and the results obtained with different road tests discussed. 


\section{INTRODUCTION}

Sustainable Mobility issues are gaining increasing attention both among specialists and in public opinion, due to the major impact of automotive systems on carbon dioxide production, climate changes and fossil fuel depletion. Recently, increasing efforts are being spent towards the application of solar energy to electric and hybrid cars. While solar vehicles do not represent a practical alternative to cars for normal use, the concept of a hybrid electric car assisted by solar panels appears more realistic [1].

In fact, thanks to a relevant research effort, in the last decade Hybrid Electric Vehicles (HEV) have evolved to industrial maturity, and represent now a realistic solution to important issues, such as the reduction of gaseous pollution in urban drive as well as the need for a substantial increase of energy conversion efficiencies. On the other hand, the use of solar energy on cars has been considered with a certain skepticism by most users, including automotive engineers. This may be due to the simple observation that the net power achievable in a car with current photovoltaic panels is about two order of magnitude less than maximum power of most of today cars. But a more careful analysis of the energy involved demonstrate that this perception may be misleading. In fact, there is a large number of drivers utilizing daily their car for short trips and with limited power demand [2]. In those conditions, the solar energy collected by solar panels on the car along a day may represent a significant fraction of the energy required for traction [3].

In spite of their potential interest, solar hybrid cars have received relatively little attention in literature. Some prototypes have been developed or are under current development [4]. Although these works demonstrate the general feasibility of such an idea, detailed presentation of results and performance, along with a systematic approach to solar hybrid vehicle design, seem still missing in literature.

Therefore, appropriate methodologies are required to address both the rapid changes in the technological scenario and increasing availability of innovative, more efficient components and solutions. A specific difficulty in developing a Hybrid Solar Vehicle relates to the many mutual interactions between energy flows, powertrain balance of plant and sizing, vehicle dimension, performance, weight and costs, whose connections are much more critical than in either conventional or Hybrid Electric Vehicles. Moreover, the control strategies for HSV cannot be simply derived from the solutions developed for HEV. In fact, the presence of solar panels requires to extend the $S O C$ management strategies also to parking phases, while the study of suitable control techniques is needed in order to maximize the net power from solar panels [5]. Finally, many HSV prototypes tend to adopt a series structure, while most of today HEV adopt a parallel or series/parallel approach. Series structure appears more suitable for plug-in hybrid applications [6], and is compatible with the use of in-wheel motors with built-in traction control and anti-skid [7]. Moreover, the series configuration represents a natural bridge towards the introduction of fuel cell hybrid vehicles.

This paper deals with modeling, on-board energy management and performance evaluation for a prototype of Hybrid Solar Vehicle with series structure. This activity has been started in the framework of the UE funded Leonardo project "Energy Conversion Systems and Their Environmental Impact" [8], a project with research and educational objectives.

\section{THE HSV PROTOTYPE}

Table 1 lists the main features and specifications of the HSV prototype (see Fig. 1), now under-development at DIMECUNISA lab facilities.

TABLE 1

Actual HSV prototype specifications

\begin{tabular}{c|c}
\hline Vehicle & Piaggio porter \\
\hline Length & $3.370 \mathrm{~m}$ \\
Width & $1.395 \mathrm{~m}$ \\
Height & $1.870 \mathrm{~m}$ \\
Drive ratio & $1: 4.875$ \\
\hline Electric motor & BRUSA MV $200-84 \mathrm{~V}$ \\
\hline Continuous power & $9 \mathrm{KW}$ \\
Peak power & $15 \mathrm{KW}$ \\
\hline Batteries & 16 VV Modules Pb-Gel \\
\hline Mass & $180 \mathrm{Ah}$ \\
\hline Capacity & Polycrystalline \\
\hline Photovoltaic panels & $1.44 \mathrm{~m}{ }^{2}$ \\
\hline Surface $A_{P V}$ & $60 \mathrm{~kg}$ \\
Weight & \\
Efficiency & 0.1 \\
(including converter) & Yanmar S 6000 \\
\hline Electric generator & $5.67 / 6.92 \mathrm{kVA}$ \\
\hline Power COP/LTP & $120 \mathrm{~kg}$ \\
\hline Weight & \\
\hline Overall weight $(w$ driver $)$ & \\
\hline MHSV & \\
\hline &
\end{tabular}

Vehicle lay-out is organized according to a series hybrid architecture, as shown in Figure 2. With this approach, the photovoltaic panels PV (placed on vehicle roof as shown in Fig. 1) assist the Electric Generator EG, powered by an Internal Combustion Engine (ICE), in recharging the Battery pack (B) in both parking mode and driving conditions, through the Electric Node (EN). The Electric Motor (EM) 


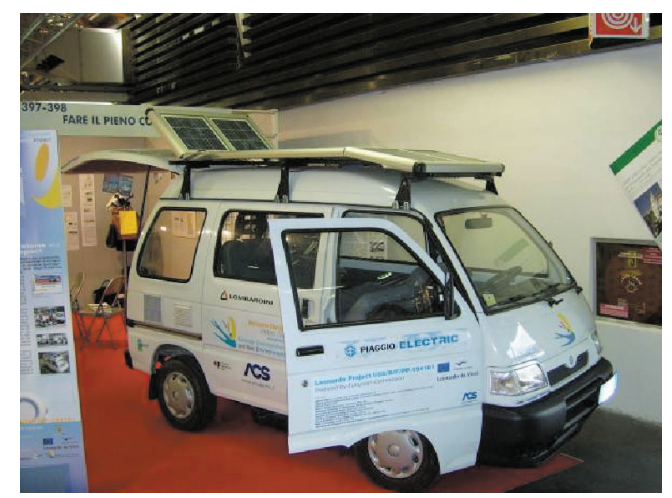

Figure 1

The hybrid solar vehicle prototype.

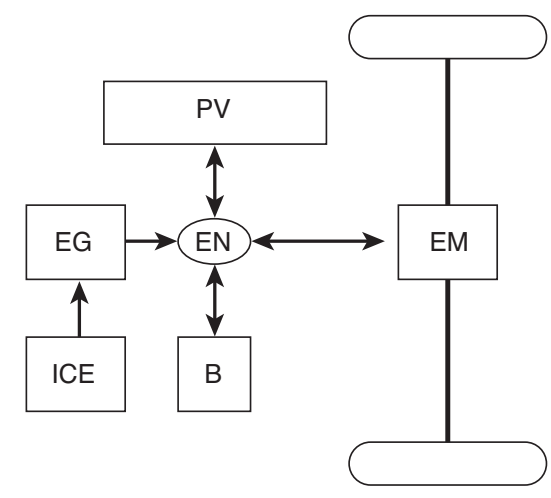

Figure 2

Scheme of the series hybrid solar vehicle. can either provide the mechanical power for the propulsion or restore part of the braking power during regenerative braking. In this structure, the thermal engine can work mostly at constant power, corresponding to its optimal efficiency, while the Electric Motor EM is designed to assure the attainment of the vehicle peak power.

\section{HSV MODELING AND EXPERIMENTAL CHARACTERIZATION}

HSV simulation, whose results are presented in Section 4, was performed by means of a longitudinal vehicle model developed under the following hypotheses:

- drag $\left(C_{x}\right)$ and rolling $\left(C_{r}\right)$ coefficients are assumed equal to 0.4 and 0.02 , respectively;

- the drag force is considered acting on vehicle centre of gravity;

- overall transmission efficiency $\eta_{\text {tr }}$ is set to 0.9;

- rotational inertia is accounted for increasing vehicle weight by $10 \%$, therefore effective mass $M_{\text {eff }}$ equals 1.1 $M_{H S V}$.

The resulting longitudinal model relates requested power at wheels to the road load, as follows:

$$
\begin{aligned}
P_{w} & =M_{H S V} \cdot g \cdot v \cdot\left[C_{r} \cos (\alpha)+\sin (\alpha)\right]+0.5 \rho C_{x} A v^{3}+ \\
& +M_{\text {eff }} \frac{d v}{d t} v
\end{aligned}
$$

where $\alpha$ and $v$ are the road grade and vehicle speed, respectively. For non negative $P_{w}$ values, the mechanical power requested to the EM is:

$$
P_{E M}=\frac{P_{w}}{\eta_{t r}} \quad \text { if } \quad P_{w} \geq 0
$$

$P_{E M}$ can also be expressed as function of power contributions coming from electric generator, battery and PV array, as follows:

$$
P_{E M}=\eta_{E M}\left(P_{E G} \cdot \eta_{A C / D C}+P_{B}+P_{P V}\right) \text { if } P_{w} \geq 0
$$

where $P_{x}$ is the power supplied by the $x$ component (i.e. electric generator, battery and photovoltaic panels), $\eta_{E M}$ is the EM efficiency and $\eta_{A C / D C}$ is the AC/DC converter efficiency, here set to 0.92 .

On the other hand, when $P_{w}<0$, the regenerative braking mode is active, resulting in the following expression for the electrical energy delivered by the EM:

$$
P_{E M}=P_{w} \cdot \eta_{t r} \cdot \eta_{E M} \quad \text { if } \quad P_{w}<0
$$

During regenerative braking, battery can be charged by EG and PV also, thus the following equation holds for negative $P_{w}$ values:

$$
P_{B}=P_{E M}-P_{E G} \cdot \eta_{A C / D C}-P_{P V} \quad \text { if } \quad P_{w}<0
$$

\subsection{Electric Generator}

The electric generator, is composed of a Diesel engine, one cylinder, $406 \mathrm{~cm}^{3}$, coupled with a 3 phase synchronous induction machine. Experiments were carried out to map the efficiency of the electric generator in a wide operating region, accounting for the whole path from fuel to electrical power. The experimental set-up was arranged with a 3-phase pure resistive, balanced electrical load. The measurements were accomplished at constant engine speed (3000 rpm), corresponding to a $50 \mathrm{~Hz}$ electric signal, with regularly spaced variation of electrical load by steps of $600 \mathrm{~W}$, up to $5400 \mathrm{~W}$. Figure 3 shows the experimental EG efficiency $v s$ the output power of the Electrical Generator (EG). The efficiency was 


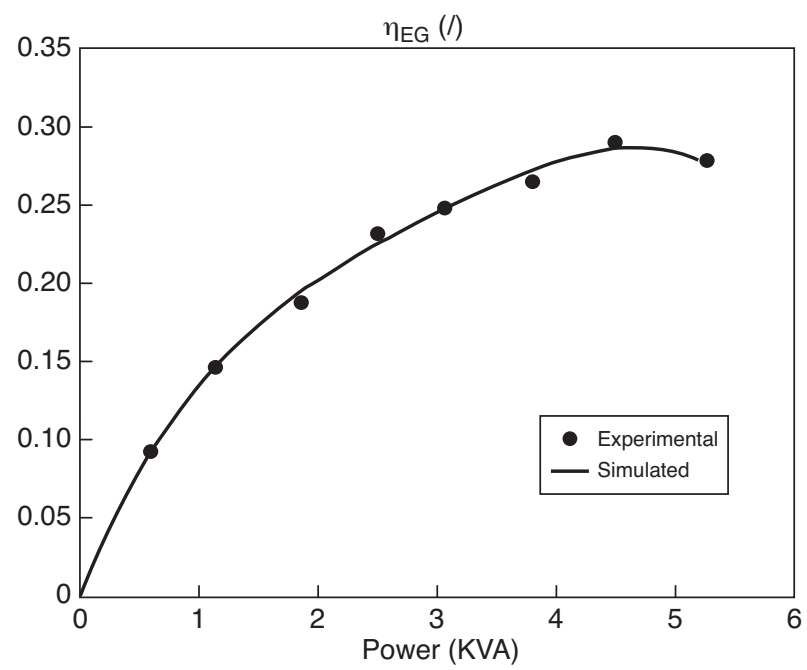

Figure 3

Comparison between experimental and predicted electric generator efficiency.

detected by processing the measurements of fuel consumption and output voltage and current, as follows:

$$
\eta_{E G}=\frac{P_{E G}}{\dot{m}_{f} H_{i}}=\frac{V \cdot I}{\dot{m}_{f} H_{i}}
$$

In Figure 3 the efficiency predicted by a black box model identified $v s$ the experimental data is also plotted. The model expresses the overall efficiency of the electric generator as function of the output electrical power by a 4 th order polynomial regression.

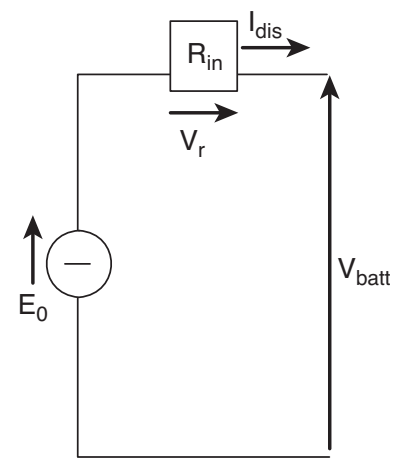

a)

$\mathrm{E}_{0}=$ Battery open circuit voltage

$\mathrm{V}_{\mathrm{r}}=$ Internal voltage losses

$I_{\text {dis }}=$ Discharging current

Figure 4

Equivalent circuit of the battery pack; a) discharge; b) charge.

\subsection{PV Array}

The PV energy contribution to vehicle traction was computed on the basis of real energy measurements collected on a stationary PV plant located within UNISA area. The measured energy distribution results in the following daily average evaluated on a year basis:

$$
E_{\text {sun,day }}=3.1 \quad\left[\frac{\mathrm{kWh}}{\mathrm{kWpday}}\right]
$$

Considering the PV roof efficiency of $10 \%$, a nominal power of $1 \mathrm{~kW}$ can be obtained with a $1 / 0.1=10 \mathrm{~m}^{2}$ array. Therefore, daily average energy yielded by the $1.44 \mathrm{~m}^{2} \mathrm{PV}$ roof (see Tab. 1) can be estimated as follows:

$$
E_{P V}=E_{\text {sun }, d a y} \cdot \frac{A_{P V}}{10}=3.1 \cdot \frac{1.44}{10}=450 \quad[\mathrm{Wh} / \mathrm{day}]
$$

\subsection{Battery Pack}

The battery pack model estimates battery State Of Charge (SOC), current and thermal state as function of the actual electrical power (i.e. positive in discharge and negative in charge). The actual current is computed starting from the electrical power, by applying the Kirchoff's law to the equivalent circuit shown in Figure 4. The internal resistance $R_{i n}$ was modeled, following the approach proposed by [9], as a nonlinear function of battery temperature and state of charge. Figure 5 focuses on the effect of SOC, showing high charge and discharge resistance at high and low SOC, respectively.

The battery model accuracy was checked by comparing simulated data with experiments conducted both in case

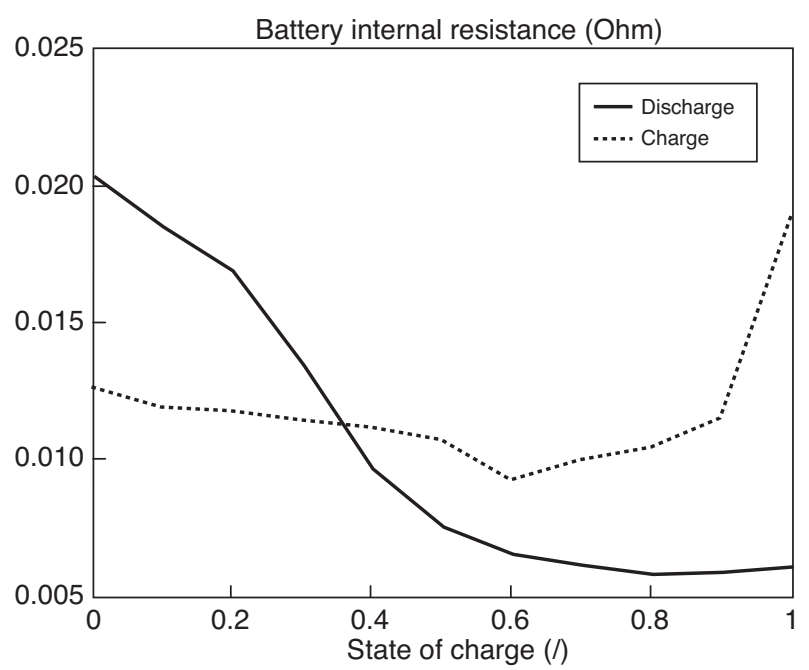

Figure 5

Variation of battery internal resistance in charging and discharging as function of $S O C$ [9]. 

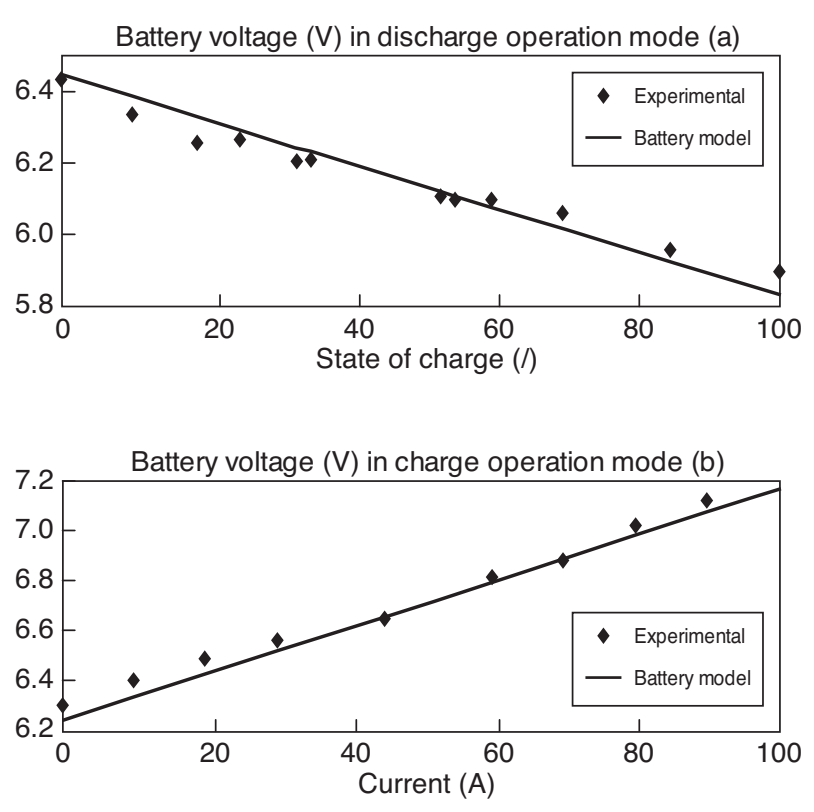

Figure 6

Comparison between model [9] and experimental data collected during battery discharging and charging.

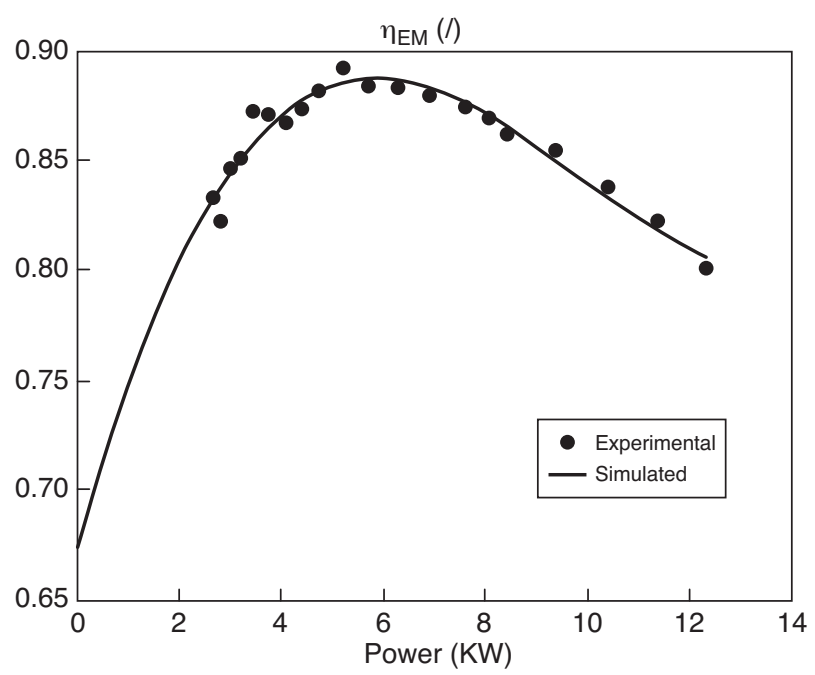

Figure 7

Comparison between experimental and predicted electric motor efficiency $v s$ provided power.

of battery discharging and charging (see Fig. 6). The agreement between experiments and model outputs confirms the validity of extending the model proposed by [9] to the battery pack the HSV prototype is equipped with. It is worth mentioning that the data shown in Figure 6 refer to initial SOC values of 1 and 0.6 for battery discharging and charging, respectively.

\subsection{Electric Motor}

The efficiency of the Electric Motor (EM) is simulated by a black box model identified $v s$ the technical data sheets provided by motor manufacturer. The model expresses the efficiency as function of the mechanical power provided for the propulsion via a 3rd order polynomial regression. Figure 7 shows both experimental and simulated efficiency $v s$ provided power.

\section{OPTIMAL ENERGY MANAGEMENT ON HSV VEHICLES}

Hybrid Solar Vehicles have of course many similarities with Hybrid Electric Vehicles, for which many studies on the optimal management and control of energy flows have been presented in last years [10-14]. Nevertheless, the presence of solar panels and the adoption of a series structure may require to study and develop specific solutions for optimal management and control of an HSV.

In fact, in most electric hybrid vehicles a charge sustaining strategy is adopted: at the end of a driving path, the battery state of charge should remain unchanged. With a solar hybrid vehicle, a different strategy should be adopted as battery is charged during parking hours as well. In this case, a different goal can be pursued, namely restoring the initial state of charge within the end of the day rather than after a single driving path [15].

Moreover, the series configuration suggests quite an efficient solution, namely to operate the engine in an intermittent way at constant operating conditions. Of course, the maximum gain in terms of fuel consumption occurs when the EG power corresponds to the most efficient value. In such case, the engine-generator system may be designed and optimized to maximize its efficiency, emissions and noise at design point, while in current automotive engines the maximum efficiency is usually sacrificed to the need of assuring stable operation and good performance in the whole operating range.

In order to develop a supervisory control to be implemented on the vehicle, a more accurate analysis of the optimal EG power distribution over an arbitrary driving cycle has to be performed. This task is discussed in the next sub-section.

\section{Optimization of Electric Generator Scheduling by Means of Genetic Algorithms}

The optimal EG power trajectory can be found by solving the following constrained optimization problem.

$$
\min _{X} \int \dot{m}_{f, H S V}(X) d t
$$

subject to the constraints:

$$
\Delta S O C_{d a y}=S O C_{f}-S O C_{0}+\Delta S O C_{p}=0
$$




$$
\begin{gathered}
S O C>S O C_{\text {min }} \\
S O C<S O C_{\text {max }}
\end{gathered}
$$

where $\dot{m}_{f, H S V}$ is the HSV fuel consumption $(\mathrm{kg} / \mathrm{s}), S O C_{f}$ and $S O C_{0}$ are the initial and final state of charge in the driving phase, respectively, and $\triangle S O C_{p}$ is the $S O C$ increase due to $\mathrm{PV}$ recharging during vehicle parking. The decision variables $X$ include number of EG-on events $N_{E G}$, along with corresponding starting time $t_{0, E G, i}$, duration $\Delta_{t, E G, i}$ and EG power level $P_{E G, i}$, where $i$ is the $i$-th EG-on event.

The first constraint (Eq. 10) allows to restore the initial state of charge within the end of the day, also considering parking phases.

It is worth noting that the proposed energy management strategy is based on the knowledge of the vehicle route. Future activities will focus on the extension of the optimization outcomes to different driving scenarios as well as insolation conditions.

The other constraints (i.e. Eq. 11 and 12) were defined accounting for internal resistance dependence on battery state of charge. Figure 5 shows that in the SOC range [0.55 0.9] both charging and discharging resistances are fairly constant while being close to their minimum values. Therefore in this analysis $S O C_{\min }$ and $S O C_{\max }$ were set to 0.55 and 0.9 , respectively.

The problem stated by Equation (9) through (12) involves both integer (e.g. $N_{E G}$ ) and real variables, thus falling in the field of Mixed Integer Programming (MIP) problems. Among the several techniques that can be adopted to solve such problems, Genetic Algorithms (GA) is one of the most efficient [16] and has thus been selected for optimizing EG scheduling on the HSV prototype.

The GA search was performed in Matlab environment by means of the GAtbx tool developed by [17]. GA optimization consists of an iterative procedure that can be schematized as follows:

- Phase 1: an initial population of $N_{\text {ind }}$ individuals (or solutions) representing the search domain (i.e. the decision variables domain) is generated randomly.

- Phase 2: an objective function $F$ is evaluated for each individual. Then, assuming that a minimization task is being accomplished, all the individuals are ranked in ascending order on the basis of their $F_{k}$ value. This way the so-called "fitness" is assigned to the $k$-th individual, whose value will range from a maximum to a minimum depending on its rank position.

- Phase 3: fitness-based selection of best individuals. According to the evolutionary theory, the best individuals have the highest probability to join the next population. The "Roulette Wheel" and "Stochastic Universal Sampling" [17] are among the most widely adopted techniques to perform a random selection of the strongest individuals as function of their fitness. Particularly, the higher its fitness is, the more likely that individual will be selected. In this work, the latter method was applied.

- Phase 4: Generation of new individuals. Phase 3 usually yields a new set of individuals containing a higher number of "strong" (i.e. with high fitness) solutions, whereas some of the weakest ones disappear. This intermediate set undergoes a renewal process consisting of two different steps: crossover and mutation. The former step basically makes a certain number of individual pairs, selected randomly, to exchange part of their genotype with each other. The resulting genotypes will of course behave differently in the next population, thus yielding a couple of new individuals. After crossover, mutation takes place, once again based on random selection of some individuals.

It is worth mentioning that an elitist approach is usually followed in Phase 4, in that some of the strongest individuals from the current population are ensured to be present in the next one. This way, even though a lower number of offsprings is introduced, the best solutions from the current population are preserved [17].

Phase 2 through Phase 4 are repeated as many times as the desired number of new generations is reached. The above description highlights the need for the decision maker to select several operating parameters $\left(N_{\text {ind }}\right.$, crossover and mutation probabilities, number of generations) depending on problem complexity and computational time requirements. Further details about GA optimization techniques can be found in the abundant literature on the topic, which the reader is addressed to [16-19].

For the current application, the following operating parameters were assumed (see Tab. 2).

TABLE 2

GA operating parameters

\begin{tabular}{l|c}
\hline$N_{\text {ind }}$ & 50 \\
Number of generations & 300 \\
Crossover probability & 0.7 \\
Mutation probability & 0.006 \\
\hline
\end{tabular}

Regarding the binary representation to define the individual genotype, the number of bits per each decision variable was calculated according to the information provided in Table 3.

TABLE 3

Binary representation of the optimization problem

\begin{tabular}{l|c|c|c}
\hline Decision variable & Definition range & Precision & Number of bits \\
\hline$N_{E G}$ & {$[14]$} & 1 & 2 \\
$t_{E G}(\min )$ & {$[053]$} & 0.055 & 10 \\
$\Delta t_{\mathrm{EG}}(\mathrm{min})$ & {$[053]$} & 0.055 & 10 \\
$P_{\mathrm{EG}}(\mathrm{kW})$ & {$[05.5]$} & 0.0055 & 10 \\
\hline
\end{tabular}




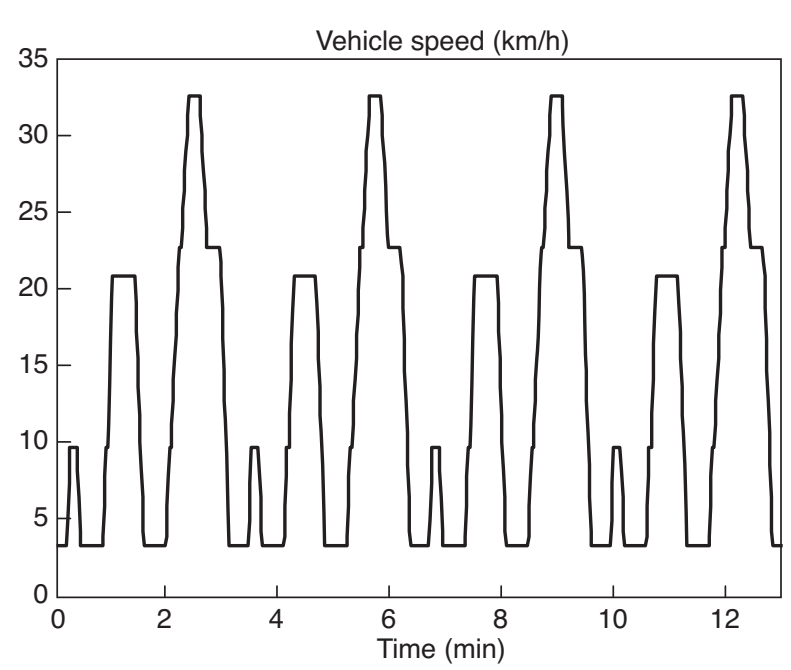

Figure 8

Module of ECE driving cycle.

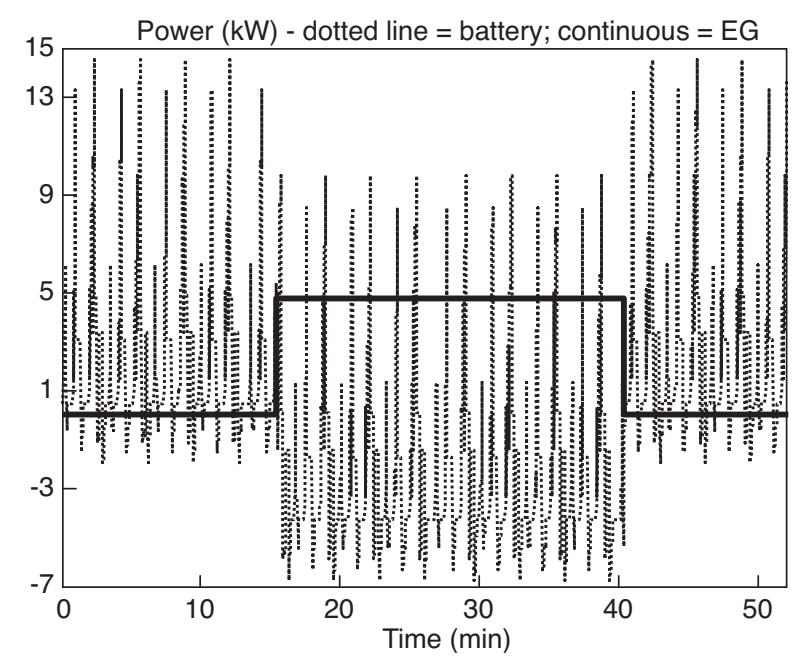

Figure 9

EG and battery power trajectories for scenario 1 .

\section{SCENARIO ANALYSIS}

In order to assess the HSV prototype performance not only at the current developmental stage, but also analyzing two further scenarios of improved vehicle configurations, a simulation analysis was performed. Such an analysis was accomplished by solving, in a backward manner, the longitudinal vehicle dynamics (i.e. Eq. 1) for a driving cycle composed of 4 ECE modules, as the one shown in Figure 8.

\section{Results}

Table 4 summarizes the results obtained in the three analyzed scenarios. Particularly, it emerges that an acceptable fuel economy can be obtained even with current vehicle configuration (i.e. scenario 1). This is possible thanks to the high efficient use of the Diesel engine addressed by the GA based optimization described above. Particularly, Figure 9 shows that the Diesel engine is turned on once, after 15 minutes, delivering $5 \mathrm{~kW}$ to battery and/or EM for about 25 minutes. This allowed to operate the EG itself at an overall efficiency as high as 0.28 (see Fig. 3). The EG energy contribution caused battery to partially recover the state of charge reduction occurred in the first part of the driving cycle, resulting in a final $S O C$ of 0.732 , as shown in Figure 10. The lower value of $S O C$ with respect to the initial one is in accordance with the constraint expressed by Equation (10).

TABLE 4

HSV simulation results

\begin{tabular}{l|c|c|c}
\hline Scenario & 1 & 2 & 3 \\
\hline$\eta_{P V}$ & 0.1 & 0.18 & 0.18 \\
Battery capacity (Ah) & 180 & 75 & 75 \\
$M_{h s v}$ & 1950 & 1658 & 1326 \\
Fuel economy (km/liter) & 15.18 & 21.70 & 29.15 \\
\hline
\end{tabular}

Regarding the other scenarios, it is worth mentioning here that the second scenario corresponds to an optimized vehicle configuration, in which a 0.18 efficient $\mathrm{PV}$ array (i.e. $E_{P V}=$ $810 \mathrm{Wh} /$ day) replaces the actual one and battery capacity is lowered down to $75 \mathrm{Ah}$. The latter hypothesis takes into account the impact of vehicle hybridization, as the added electric generator allows to reduce both battery storable energy and nominal power. The lower battery capacity also causes the weight to decrease from $1950 \mathrm{~kg}$ to $1658 \mathrm{~kg}$. Such a configuration results in a fuel economy improvement up to $22 \mathrm{~km} /$ liter, as indicated in Table 4. Figure 11 shows that in scenario 2 the optimal EG scheduling addressed by the GA optimization consists of two EG-on events and lower average EG power with respect to scenario 1, which in turn results in a lower energy contribution by the EG. This is linked to the lower final SOC to be reached at the end of the driving phase (see Fig. 10) as compared to scenario 1. The low final SOC (about 0.675) is due to the higher amount of solar energy and the lower battery capacity simulated in scenario 2 . In conclusion, both weight reduction and PV efficiency increase contribute to achieve the fuel economy improvement. Particularly, the fuel saving is equivalent to 0.2 liter in the reference transient and is due by $56 \%$ to weight reduction and by $44 \%$ to PV efficiency.

Finally, the third scenario was considered to account for a further weight reduction (i.e. 20\%), obtainable by improving vehicle materials [3]. The simulated fuel economy in this case gets close to $30 \mathrm{~km} / \mathrm{liter}$. As in scenario 2 , the final SOC sets to 0.675 , as shown in Figure 10. On the other hand, the energy contribution requested to the EG is further low as compared to scenario 2, due to the lower vehicle weight 


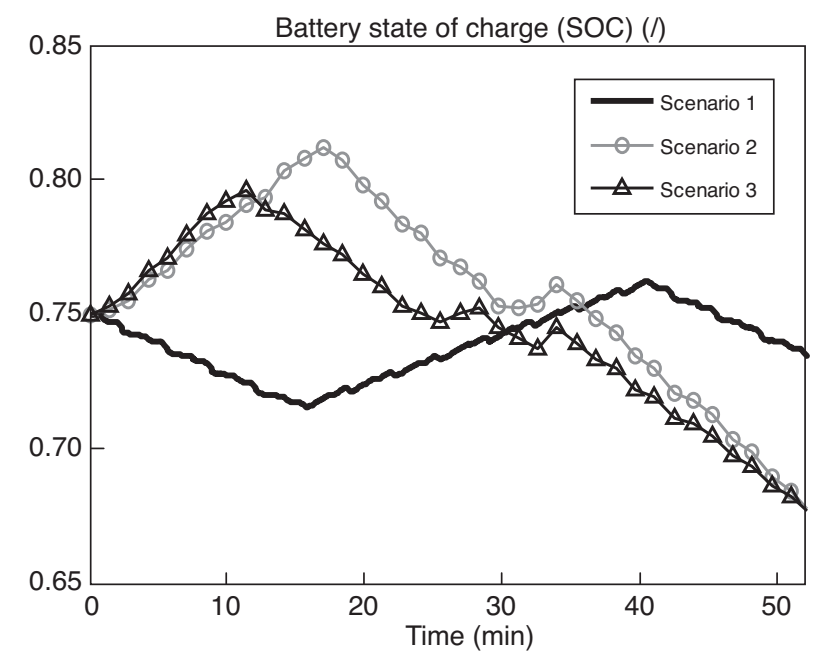

Figure 10

SOC trajectories for all simulated scenarios.

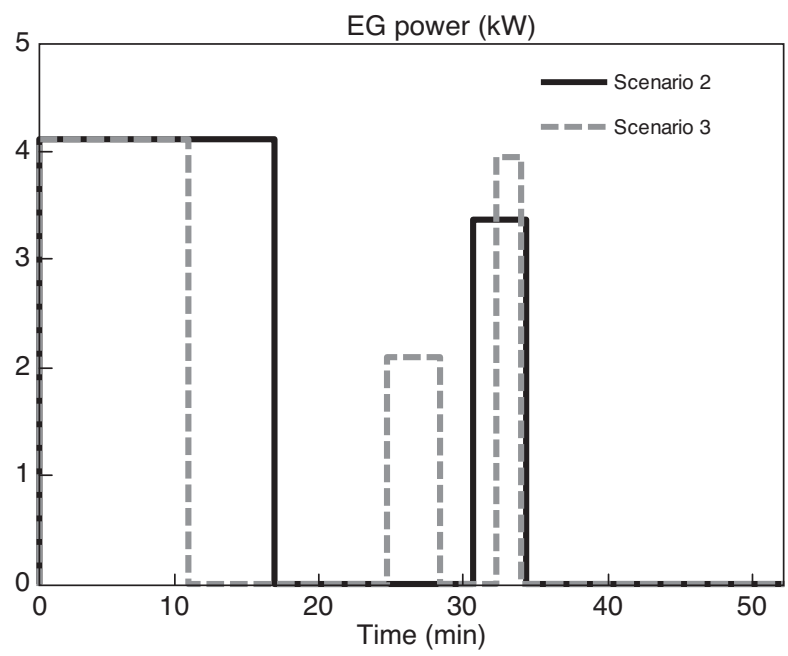

Figure 11

EG power trajectories for scenarios 2 and 3. assumed in scenario 3. In order to maximize fuel economy, this time the GA optimization yielded a solution with 3 EGon events, each one with shorter duration than scenario 2 but similar average power, as shown in Figure 11. On the other hand, both in scenario 2 and 3 a lower number of EG-ON events would have entailed reducing average PEG, which in turn would have caused fuel economy to reduce due to less efficient ICE functioning.

\section{EXPERIMENTAL RESULTS ON THE HSV PROTOTYPE}

The HSV prototype has been equipped with a programmable NI-cRio ${ }^{\circledR}$ control unit, which interfaces with the real system to pursue the following aims:

a. Data acquisition

b. Real time Control of ICE-EG start\&stop

c. Data logging

Figure 12 illustrates the measure chain adopted to address points a and c. An interesting feature of the available HSV test bench is represented by the torque meter (see Fig. 13), which allows precise estimation of traction power demand, on one hand, and to deeply assess regenerative braking contribution, on the other.

Regarding point $\mathrm{b}$, some preliminary experimental tests were performed imposing fixed lower and upper SOC thresholds, beyond which the ICE-EG is turned on and off, respectively. Figure 14 provides a simple schematic of the control strategy adopted in this preliminary experiment. ICE start\&stop strategy can thus be introduced depending on online estimation of current state of charge, which was performed by implementing the battery model (see Sect. 2.3) in LabView-cRio environment ${ }^{\circledR}$.

Figure 15 through Figure 17 show some of the experimental measurements collected during the road test. Figure 15a

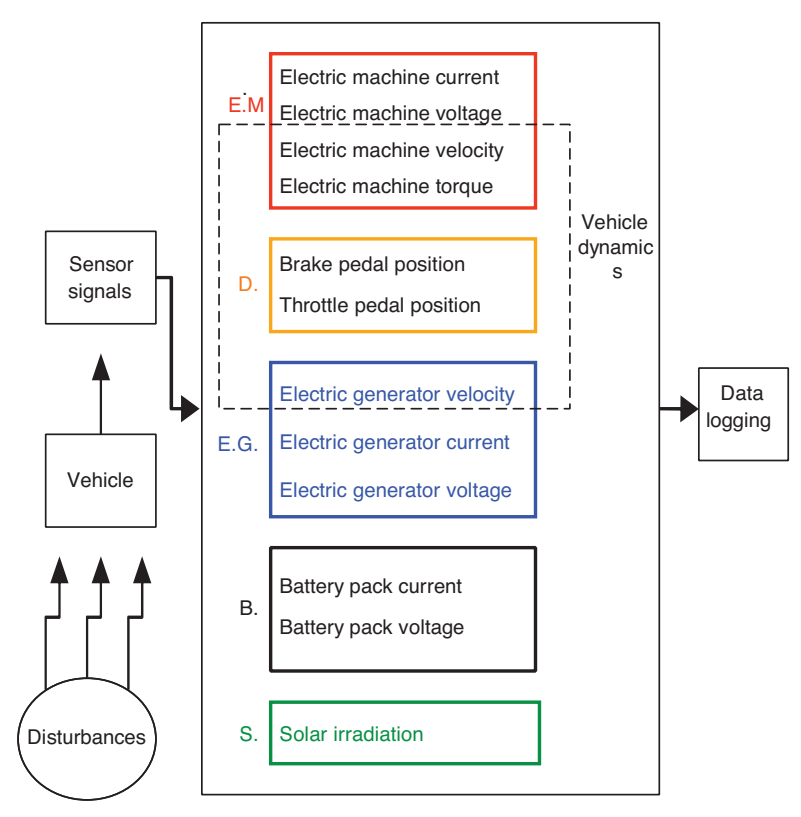

Figure 12

Schematic representation of the acquisition system.

shows that ICE-EG is kept on until Battery SOC remains below the upper threshold, here set to 0.576 . Then, after approximately 6.5 minutes, ICE-EG is turned off, causing SOC to decrease down to the low threshold (i.e. 0.57) after 10 minutes (see Fig. 15b). Afterwards, the ICE-EG is continuously on until almost the end of the driving cycle (see Fig. $15 a$ ), thus ensuring a charge sustaining strategy. Figure 16 shows a close window of acceleration pedal position, EM shaft torque and battery-current profiles. As expected, when the pedal is fully pushed (i.e. position $=1$ ) high torque and 


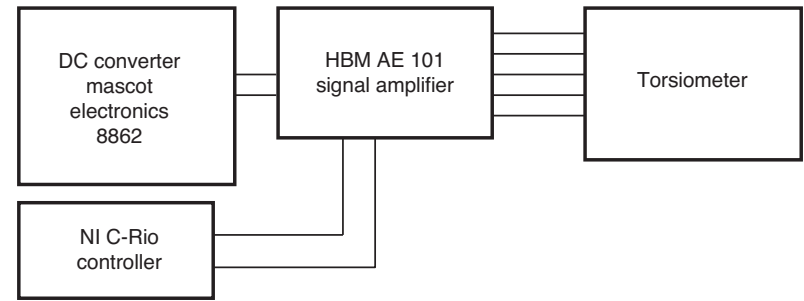

Figure 13

Measurement Scheme for real-time monitoring of traction torque.

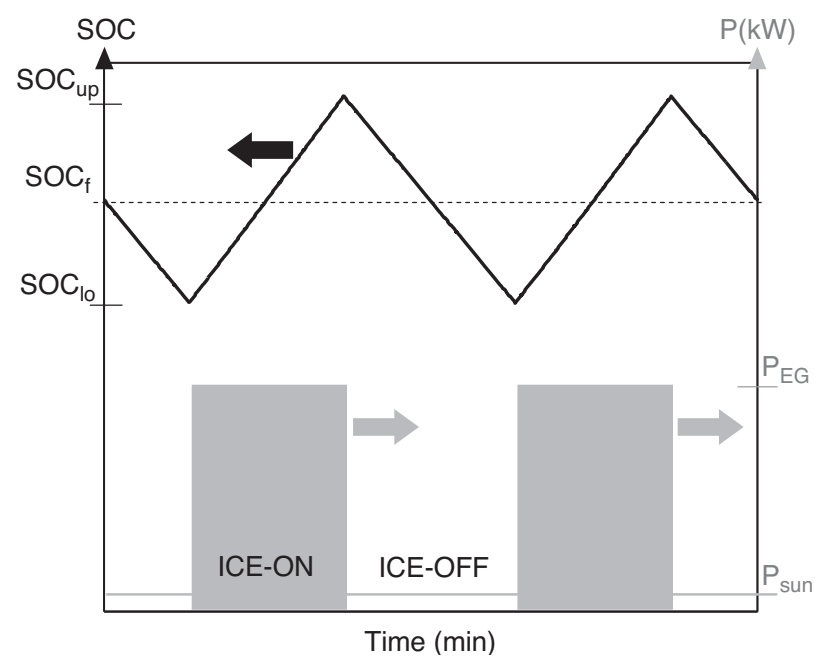

Figure 14

ICE-EG heuristic control logic adopted in the experimental test.

current occur. On the other hand, when the pedal is released, negative torque and current are sensed, thus indicating that regenerative braking mode is active on the HSV.

Finally, Figure 17 shows the PV power trajectory, indicating that a maximum of $80 \mathrm{~W}$ solar contribution was reached during the driving phase. Despite the low solar power sensed during the driving route, the subsequent parking contribution allowed increasing fuel economy from $13.8 \mathrm{~km} / 1$ (i.e. derived from the sole driving phase measurement) up to $14.6 \mathrm{~km} / 1$. These results are in good accordance with ECE simulations described in Table 4 and confirm the suitability of the HSV test bench to develop and test model-based control strategies. Particularly, such an experimental set-up will allow, on one hand, to verify the control actions addressed by the GAbased optimization procedure presented in the previous section. On the other hand, the developed NI-cRio ${ }^{\circledR}$ control\&monitoring platform is suitable to develop and implement heuristic energy management rules to be adopted for real time energy management of HSVs.
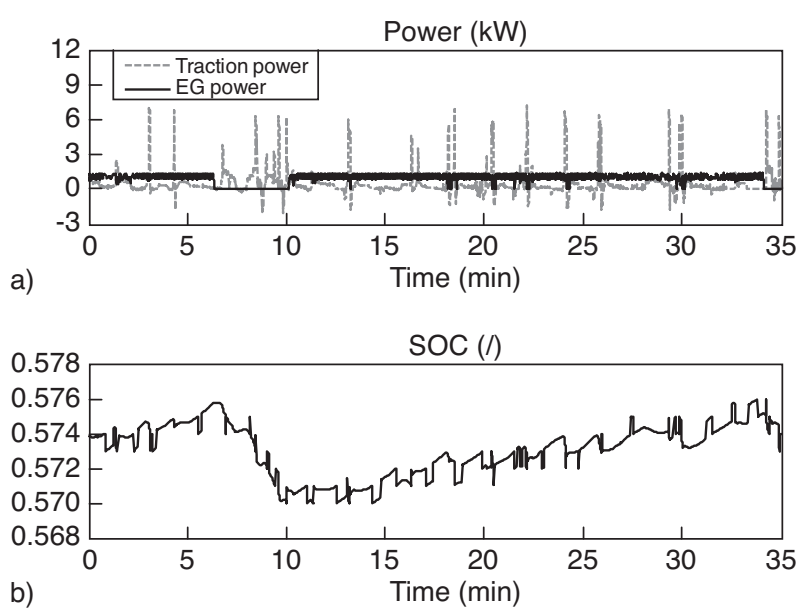

b)

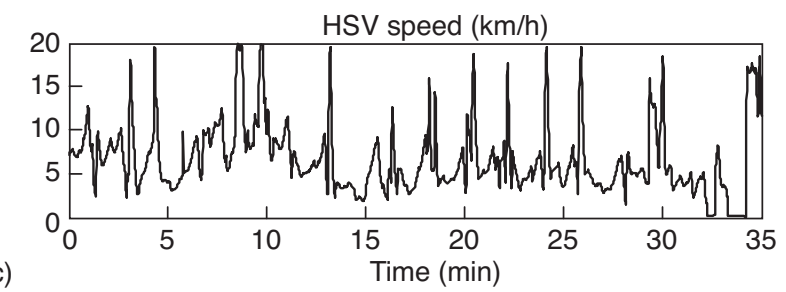

Figure 15

Measured time trajectories of main acquired signals.
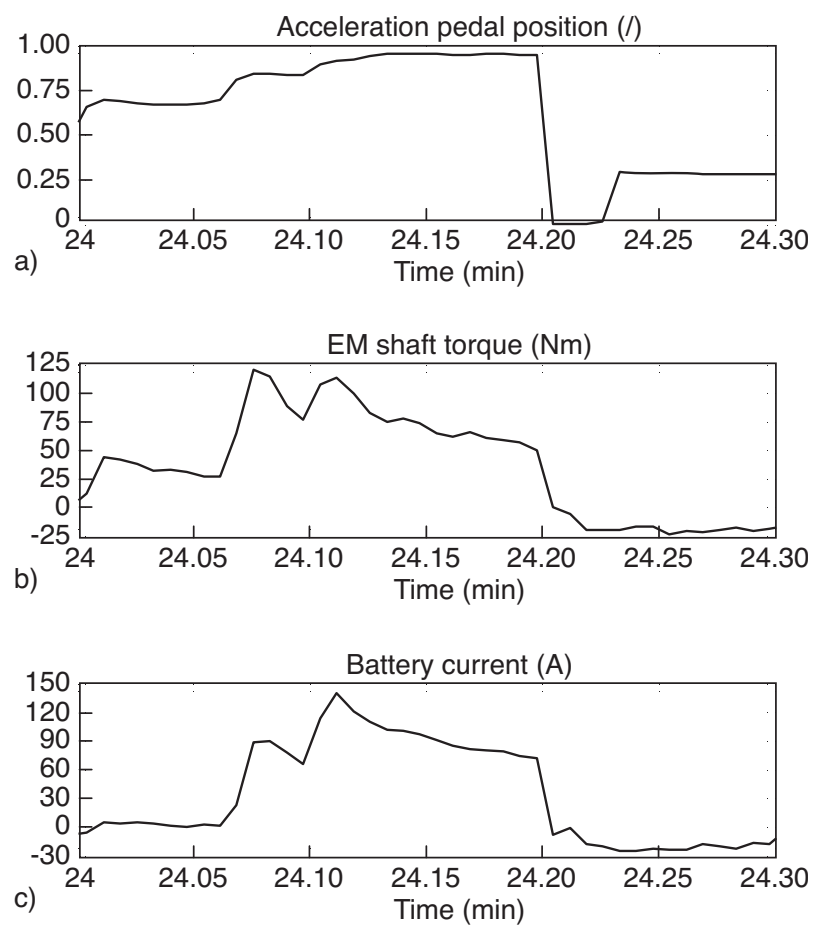

Figure 16

Close windows of acceleration pedal position, electric motor shaft torque and battery current measured profiles. 


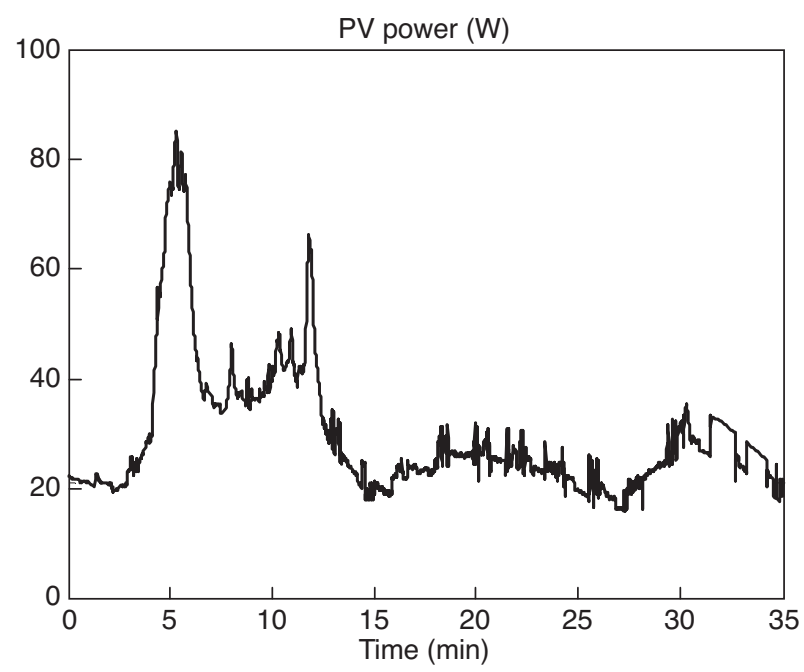

Figure 17

PV array power trajectory measured during the road test.

\section{CONCLUSIONS}

The paper reported on the actual developmental stage of a hybrid solar vehicle prototype. The experimental and numerical activities conducted to develop and validate a comprehensive HSV model were presented. The model accounts for vehicle longitudinal dynamics along with the accurate evaluation of energy conversion efficiency for each powertrain component.

Genetic algorithm optimization was proposed to address some of the most challenging issues in the development of hybrid solar vehicles with series structure, namely the definition of the optimal electric generator scheduling.

Actual vehicle performance and fuel economy were analyzed by simulating the HSV prototype on a driving route composed of 4 ECE cycles. The resulting fuel consumption was $15 \mathrm{~km} /$ liter. Further simulations showed that fuel economy can be increased up to $30 \mathrm{~km} / \mathrm{liter}$ both by substituting the actual PV array with more advanced solar technology and by appropriately resizing HSV components.

On-going and future activities focus on numerical, experimental and prototype developmental tasks. Particularly, the GA based optimization procedure for EG scheduling will be adopted as a reference benchmark to assess the effectiveness of rule-based control strategies (e.g. similar to those shown in Fig. 14) for real time energy management of HSVs. In parallel, suited on the-road test and measurements will be performed to validate both simulation results and energy management performances. Regarding prototype improvements, the installation of an automated sun-tracking roof to further enhance solar energy captation is under current study.

\section{ACKNOWLEDGMENTS}

The authors would like to acknowledge the European Union, the Italian Ministry of University and Research and the University of Salerno for their support to the research activity presented in this paper.

\section{REFERENCES}

1 Neil C. (2006) Solar Hybrid Vehicles, Energy Pulse, available at www.energypulse.net.

2 Statistics for Road Transport, available at www.statistics.gov.uk/CCI/nscl.asp? ID=8100.

3 Arsie I., Marotta M., Pianese C., Rizzo G., Sorrentino M. (2005) Optimal Design of a Hybrid Electric Car with Solar Cells, Proc. of 1st AUTOCOM Workshop on Preventive and Active Safety Systems for Road Vehicles, Istanbul, Sept. 1921.

4 Fiat Phylla (2008) www.motorauthority.com/ cars/fiat/fiatphylla-concept-previews-new-topolino-electric-minicar/.

5 Petrone G., Femia N., Spagnuolo G., Vitelli M. (2005) Optimization of perturb and observe maximum power point tracking method, IEEE T. Power Electr. 20, 963-973.

6 Letendre S., Perez R., Herig C. (2003) Vehicle Integrated PV: A Clean and Secure Fuel for Hybrid Electric Vehicles, Proc. of the American Solar Energy Society Conference, June 21-23, Austin, TX.

7 www.itee.uq.edu.au/ serl/UltraCommuter.html.

8 Leonardo Program "Energy Conversion Systems and Their Environmental Impact", http://www.dimec.unisa.it/leonardo.

9 Burch S., Cuddy M., Johnson V., Markel T., Rausen D., Sprik S., Wipke K., ADVISOR: Advanced Vehicle Simulator, available at http://www.avl.com/advisor.

10 Powell B.K., Bailey K.E., Cikanek S.R. (1998) Dynamic modeling and Control of Hybrid Vehicle Powertrain Systems, IEEE T. Contr. Syst. 18, 5.

11 Baumann B., Rizzoni G., Washington G. (1998) Intelligent Control of Hybrid Vehicles using Neural Networks and Fuzzy Logic, SAE paper 981061.

12 Guzzella L., Amstutz A. (1999) CAE Tools for Quasi-Static Modeling and Optimization of Hybrid Powertrains, IEEE T. Veh. Technol. 48, 6, November.

13 Arsie I., Graziosi M., Pianese C., Rizzo G., Sorrentino M. (2005) Optimization of Supervisory Control Strategy for Parallel Hybrid Vehicle with Provisional Load Estimate, JSAE Rev. Automotive Eng. 26, 3, 341-348.

14 Arsie I., Di Martino R., Rizzo G., Sorrentino M. (2008) Energy Management for a Hybrid Solar Vehicle with Series Structure, Proc. of the 17th IFAC World Congress, July 6-11, 2008, Seoul, Korea.

15 Arsie I., Rizzo G., Sorrentino M. (2007) Optimal Design and Dynamic Simulation of a Hybrid Solar Vehicle, SAE paper 2006-01-2997, SAE Trans. - J. Eng. 115, 3.

16 Sakawa M., Kato K., Ushiro S., Inaoka M. (2001) Operation planning of district heating and cooling plants using genetic algorithms for mixed integer programming, Appl. Soft Computing 1, 139-150. 
17 Chipperfield A.J., Fleming P.J., Polheim H., Fonseca C.M. (1996) Genetic Algorithm Toolbox - Matlab Tutorial, Department of Automatic Control and System Engineering University of Sheffield, downloadable at: http://www.shef.ac.uk/acse/research/ecrg/getgat.html.

18 Chipperfield A.J., Fleming P.J., Fonseca C.M. (1994) Genetic Algorithm Tools for Control Systems Engineering, Proc. Adaptive Computing in Engineering Design and
Control, Plymouth Engineering Design Centre, 21-22 September, pp. 128-133.

19 Zitzler E. (1999) Evolutionary Algorithms for Multiobjective Optimization: Methods and Applications, Ph.D. Thesis, ETH Swiss Federal Institute of Technology, Zurich, Switzerland.

Final manuscript received in April 2009 Published online in September 2009 